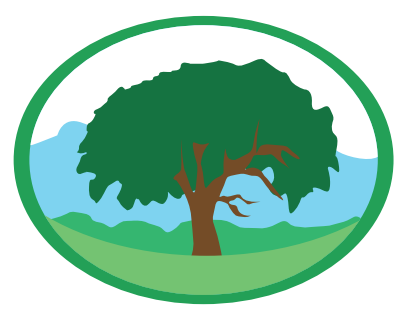

\title{
Caracterização de biomassa visando à produção de etanol de segunda geração
}

VITÓRIA QUINCOSES AZEVEDO', CLÁUDIA FERNANDA LEMONS E SILVA², JULIANA SILVA LEMÕES³,

\section{SABRINA PERES FARIAS4.}

\author{
'Universidade Federal de Pelotas - vitaazevedolahotmail.com \\ ${ }^{2}$ Centro de Engenharias/UFPel - lemonsclaudagmail.com \\ ${ }^{3}$ Instituto de Química/UFRGS - julianalemoesdyahoo.com.br \\ ${ }^{4}$ Universidade Federal de Rio Grande - s.pfariasđyahoo.com.br
}

Palavras-chave: celulose, hemicelulose, lignina, prétratamento

\begin{abstract}
Resumo
Deve-se conhecer detalhadamente a biomassa a ser utilizada em um processo, pois são essas características que irão fornecer informações para determinar o método a ser utilizado. Nesse contexto, o presente estudo objetivou a caracterização das biomassas de arundo, palha e casca de arroz quanto ao teor de celulose, hemicelulose e lignina antes e após o pré-tratamento. A caracterização foi feita de acordo com a metodologia descrita por Dunning e Dallas (1949) e os cálculos a partir das equações descritas por Sluiter et al. (2005). Os valores encontrados para as biomassas in natura foram, arundo $32,3 \%$ de celulose, $41,5 \%$ de hemicelulose e $20,9 \%$ de lignina, para casca de arroz 30,4, 31,2 e 21,2\% e palha de arroz $36,9,36,8$ e 13,3\% respectivamente. Já para as biomassas pré-tratadas, os teores encontrados de celulose, hemicelulose e lignina foram arundo 69,5, 15,5 e $10,2 \%$, casca de arroz $62,4,22,7$ e $14,8 \%$ e palha de arroz $78,4,16,1$ e $5,3 \%$ respectivamente. Para as biomassas pré-tratadas a fração de celulose aumentou em relação às biomassas in natura e a de hemicelulose e lignina diminuíram. Como o objetivo é a produção de etanol de segunda geração através da fração celulósica, essa diminuição é desejável e indica uma grande solubilização da fração hemicelulósica e de lignina.
\end{abstract}

\section{Falta o título em inglês}

Keywords: cellulose, hemicellulose, lignin, pretreatment

\begin{abstract}
It is very important to know the details of the biomass to be used in a process, because their specific characteristics will provide the necessary information to determine the method to be utilized. In this sense, this study objective is the characterization of the biomasses of arundo, straw, and rice husk as the content of cellulose, hemicelluloses, and lignin before and after treatment. The characterization was made according to the methodology described by Dunning and Dallas (1949) and the calculations according to Sluiter et al. (2005) described equations. The values found for the biomasses in natura were as follows: arundo $32.3 \%$ cellulose, $41.5 \%$ hemicellulose and lignin $20.9 \%$, rice husk $30.4 \%, 31.2 \%$, and $21.2 \%$, and rice straw $36.9 \%, 36.8 \%$, and $13.3 \%$, respectively. For the pretreated biomasses, the levels found of cellulose, hemicelluloses, and lignin were: arundo $69.5 \%, 15.5 \%$, and $10.2 \%$, rice husk $62.4 \%, 22,7 \%$, and $14.8 \%$, rice straw $78.4 \%, 16.1 \%$, and $5.3 \%$, respectively. In the pre-treated biomasses the fraction of cellulose increased relatively to the biomasses in natura, for the hemicellulose
\end{abstract}


and lignin they decreased. Since the goal is the second generation ethanol production through cellulosic fraction, this reduction is desirable and indicates a large solubilization of hemicellulose and lignin fraction.

\section{INTRODUÇÃO}

Novas alternativas para geração de energia que sejam renováveis e que não prejudiquem o meio ambiente têm sido buscadas. Uma alternativa são os biocombustíveis, como o etanol de segunda geração, que tem um potencial promissor devido ao fato de que a matéria-prima utilizada para sua produçáo é um subproduto das atividades agrícolas, e por apresentar poucos nutrientes não serve para alimentação humana e animal. Por este motivo, o aproveitamento desses resíduos para a produção de combustível é uma forma extremamente vantajosa para a destinação final da biomassa (HICKERT, 2010).

Outra vantagem de utilizar essas biomassas é que diminui consideravelmente a competição pelo uso da terra para produção de alimentos. Sem precisar ampliar os canaviais, usando apenas a palha e o bagaço, o Brasil tem potencial de aumentar em $50 \%$ a produção de etanol (STAVELA; ARAÚJO; PORTO, 2014). Apesar das grandes vantagens, ainda são encontradas algumas dificuldades, como por exemplo, tecnologias que não estão completamente desenvolvidas, com baixo rendimento na conversão da matéria-prima em bioetanol e com custo de produção elevada.

Qualquer matéria que tenha em sua composição açúcar ou outro carboidrato pode ser utilizada como matéria-prima para produção de etanol. De acordo com o tipo de carboidratos presentes na matériaprima, elas podem ser classificadas em três grupos diferentes: materiais açucarados, materiais amiláceos e lignocelulósicos, sendo este último grupo provenientes de vegetais que necessitam de pré-tratamento físico e químico vigorosos para obtenção de etanol, como casca e palha de arroz, arundo, entre outros (BARCELOS, 2012).

As fontes renováveis mais encontradas na natureza são as biomassas lignocelulósica (CASTRO; PEREIRA JR, 2010), por isso tornam-se atrativas para produção de etanol de segunda geração. Essas biomassas são constituídas por três principais polímeros: lignina, hemicelulose e celulose (SOUSA, 2014).
Sáo encontrados cerca de 40-60\% de celulose, 20$40 \%$ de hemicelulose e 15-25\% de lignina (PEREIRA JR et al., 2008), porém a proporção destes componentes pode variar dependendo da espécie da planta, idade, tempo de colheita e condição ou estágio de crescimento (BARCELOS, 2012). Por este motivo, se faz necessário conhecer a estrutura e as características dos principais componentes da biomassa lignocelulósica: celulose, hemicelulose e lignina.

O Arundo donax L. é uma planta que apresenta um grande potencial para produção de etanol de segunda geração, por se adaptar facilmente em qualquer condição ambiental. Apesar de exigir grandes quantidades de água para seu crescimento, apresenta pouca exigência acerca da fertilidade do solo, tem um crescimento rápido e uma produtividade elevada (SOUZA, 2014).

Outra cultura que apresenta grande potencial para aproveitamento de biomassa é a cultura do arroz irrigado. Com cerca de 11 milhóes de toneladas de arroz o Brasil está entre os dez principais produtores mundiais deste grão. A região sul contribui com cerca de $77 \%$ da produçáo nacional, sendo o Rio Grande do Sul o maior produtor brasileiro, com $65 \%$ desta produçáo (BRASIL, 2014). Com esse aumento da produção, aumenta-se também a quantidade de resíduos gerados, na qual se destacam a palha e a casca de arroz.

Para que se tenha uma maior eficiência na obtenção de biocombustível é necessário conhecer profundamente a biomassa que será utilizada. Isso porque é esta caracterização que irá fornecer informaçóes importantes para que seja determinado o melhor processo ou método a ser utilizado, e assim, obter maiores rendimentos, minimizar custos e impactos ambientais (OLIVEIRA, 2013). Nesse contexto, o presente estudo objetiva a caracterização das biomassas de arundo, palha e casca de arroz quanto ao teor de celulose, hemicelulose e lignina antes e após o pré-tratamento.

\section{MATERIAL E MÉTODOS}

\section{Preparo da amostra}

Para este trabalho foram selecionadas as biomassas 
de Arundo donax L. (planta inteira) e Oriza sativa L., cultivar Puitá (casca e palha de arroz).

As biomassas pré-tratadas foram adquiridas do trabalho realizado por FARIAS et al. (2014) cujo pré-tratamento ácido foi feito com $\mathrm{H} 2 \mathrm{SO} 4$ 1,1\% e o alcalino com $\mathrm{NaOH} 0,5 \mathrm{M}$.

\section{Caracterização da biomassa}

A análise para caracterização química das biomassas in natura e pré-tratadas foi feita de acordo com a metodologia descrita por Dunning e Dallas (1949), que se fundamenta na sacarificaçáo quantitativa dos polissacarídeos de diferentes matérias-primas vegetais.

Foram pesadas separadamente em balança analítica 2,0 g de amostra previamente seca em estufa durante $24 \mathrm{~h}$ e peneiradas a fim de selecionar as fraçóes granulométricas reduzidas (utilizaram-se peneiras de 32 mesh). As amostras foram transferidas para béqueres de $100 \mathrm{~mL}$ e adicionados $10 \mathrm{~mL}$ de ácido sulfúrico $72 \% \mathrm{v} / \mathrm{v}$. A mistura foi levada para banhomaria a $45^{\circ} \mathrm{C}$, por 7 min e agitada constantemente com bastão de vidro. Após esta etapa, as amostras foram transferidas para erlenmeyers de $500 \mathrm{~mL}$ e adicionados $275 \mathrm{~mL}$ de água destilada. Os frascos foram fechados com papel alumínio e levados para autoclavar por 30 min a uma temperatura de $121^{\circ} \mathrm{C}$. Depois de retiradas da autoclave e esfriadas a temperatura ambiente, as amostras foram filtradas a vácuo com o objetivo de separar a fração sólida da líquida. A fração sólida foi colocada em cadinhos de porcelana (previamente secados e pesados) e a fração líquida foi transferida para baláo volumétrico de $500 \mathrm{~mL}$, o qual teve seu volume ajustado com água destilada.

Para determinação da lignina, a fração sólida foi secada em estufa a temperatura de $100^{\circ} \mathrm{C}$, por $24 \mathrm{~h}$ e em seguida pesada em balança analítica (W1). Logo após, a amostra foi calcinada a $550^{\circ} \mathrm{C}$. Depois de resfriados, os cadinhos foram pesados (W2).

Já, a fração líquida foi utilizada para determinação da concentração de glicose $(\mathrm{C} 1)$ e de açúcares redutores totais (C2) utilizando os métodos enzimáticos de glicose oxidase (kit enzimático) e DNS (Ácido 3,5 dinitro salicílico).

\section{Análises}

Os valores de celulose, hemicelulose e lignina foram calculados a partir das equaçóes descritas por Sluiter et al. (2005).

\section{Celulose}

O teor de celulose foi calculado pela Eq. 1:

celulose $\left(\% \frac{m}{m}\right)=100 \mathcal{C}_{1} \frac{0,9 \mathrm{v}}{0,96 \mathrm{~m}}$

Onde

0,90 - coeficiente que resulta da relação entre peso molecular do polímero e do monômero de glicose;

0,96 - rendimento da sacarificação;

$\mathrm{C} 1$ - concentração de glicose $(\mathrm{g} / \mathrm{L})$;

v - volume total da solução de açúcar (L);

$\mathrm{m}$ - massa da amostra seca (g).

\section{Hemicelulose}

O teor de hemicelulose foi calculada pela Eq. 2:

$$
\text { hemicelulos }\left(\% \frac{m}{m}\right)=100\left(c_{2}-c_{1}\right) \frac{0,88 \mathrm{v}}{0,93 \mathrm{~m}} \text { (2) }
$$

Onde

0,88 - coeficiente que resulta da relaçáo entre peso molecular do polímero e do monômero; 0,93 - rendimento da sacarificação;

$\mathrm{C} 1$ - concentração de glicose $(\mathrm{g} / \mathrm{L})$;

$\mathrm{C} 2$ - concentração de açúcares redutores $(\mathrm{g} / \mathrm{L})$;

v - volume total da solução de açúcar (L);

$\mathrm{m}$ - massa da amostra seca (g).

\section{Lignina}

O teor de lignina foi calculado pela Eq. 3:

$\operatorname{lignina}\left(\% \frac{m}{m}\right)=100 \frac{\left(w_{1}-w_{2}\right)}{m}$

Onde

W1- Resíduo seco da filtragem (g);

W2 - Peso do resíduo após calcinação (g)

m - massa da amostra seca (g).

\section{Método enzimático de glicose oxidase (C1)}

Para determinação de glicose foram adicionados $10 \mu \mathrm{L}$ de amostra em tubos eppendorf de $2 \mathrm{~mL}$, em seguida adicionado $1 \mathrm{~mL}$ de reagente GOD (kit 
enzimático AA Wierner Lab.) aos tubos e então estes foram homogeneizados. Os tubos foram colocados em banho-maria a $37^{\circ} \mathrm{C}$ durante 15 min e logo após, adicionado $1 \mathrm{~mL}$ de água destilada. A leitura foi realizada em espectrofotômetro em comprimento de onda de $505 \mathrm{~nm}(\lambda=505 \mathrm{~nm})$.

\section{Método para determinar a concentração de açúcares redutores totais (C2)}

Foram retirados $100 \mu \mathrm{L}$ de amostra da fração líquida que foi separada anteriormente e colocados em tubos eppendorff de $2 \mathrm{~mL}$. Em seguida, foram adicionados $300 \mu \mathrm{L}$ de soluçáo DNS aos tubos e então estes foram homogeneizados. Os tubos foram colocados em banho-maria fervente durante 5 min e depois de retirados, foram resfriados em banho de gelo e acrescentados aos tubos $1 \mathrm{~mL}$ de água destilada em cada um. A leitura foi realizada em espectrofotômetro com comprimento de onda de $540 \mathrm{~nm}(\lambda=540 \mathrm{~nm})$.

\section{RESULTADOS E DISCUSSÃO}

\section{Caracterização das biomassas}

Os resultados de composição química das biomassas in natura analisadas são apresentados na Tabela 1. Em percentagem, as quantidades de celulose e hemicelulose são semelhantes. Para o arundo e a casca de arroz, a fração de hemicelulose foi superior a de celulose, o que mostra que pode ser interessante utilizar essa fraçáo para produção de etanol, já que em sua composição há uma grande quantidade de açúcares. Para a maioria das espécies, a fração de celulose é maior que a de hemicelulose.

Composição química das biomassas in natura de arundo, palha e casca de arroz.

\begin{tabular}{|l|l|l|l|}
\hline & $\begin{array}{l}\text { CELULOSE } \\
(\%)\end{array}$ & $\begin{array}{l}\text { HEMICELULOSE } \\
(\%)\end{array}$ & $\begin{array}{l}\text { LIGNINA } \\
(\%)\end{array}$ \\
\hline Arundo & 32,3 & 41,52 & 20,89 \\
\hline Casca de Arroz & 30,36 & 31,17 & 21,20 \\
\hline Palha de Arroz & 36,98 & 36,87 & 13,34 \\
\hline
\end{tabular}

No estudo realizado por Hickert (2010) foram encontrados $34 \%$ de celulose, $13 \%$ de hemicelulose e $20 \%$ de lignina para a casca de arroz. Roberto et al. (2003) encontrou para palha de arroz valor de celulose maior que o encontrado no presente trabalho, sendo $43 \%$ de celulose, $22 \%$ de hemicelulose e $17 \%$ de lignina, enquanto que foram encontrados valores de $36,98 \%$, 36,87\% e $13,34 \%$, respectivamente.

Já, no trabalho realizado por Lemons e Silva et al. (2015), a composição química para o arundo foi de $31,10 \%$ de celulose, $35,27 \%$ de hemicelulose e $18,5 \%$ de lignina. Apesar dos valores encontrados para as fraçóes celulósica e de lignina serem próximos, o valor da hemicelulose no presente trabalho foi maior do que aquele encontrado por Lemons e Silva et al. (2015). Essas diferenças de valores podem ocorrer devido à variabilidade natural de composição química das matérias-primas ou época de colheita, ou seja, o fato pode estar associado à origem da biomassa ou até mesmo ao método de análise utilizado (CARMO, 2013).

Para as biomassas pré-tratadas, os valores de celulose, hemicelulose e lignina estão representados na tabela 2. Pode -se observar que a quantidade de celulose para as três biomassas pré-tratadas aumentou em relação às biomassas in natura e a de hemicelulose e lignina diminuíram.

Composição química das biomassas prétratadas de arundo, palha e casca de arroz.

\begin{tabular}{|l|l|l|l|}
\hline & $\begin{array}{l}\text { CELULOSE } \\
(\%)\end{array}$ & $\begin{array}{l}\text { HEMICELULOSE } \\
(\%)\end{array}$ & $\begin{array}{l}\text { LIGNINA } \\
(\%)\end{array}$ \\
\hline Arundo & 69,48 & 15,55 & 10,17 \\
\hline Casca de Arroz & 62,43 & 22,70 & 14,79 \\
\hline Palha de Arroz & 78,42 & 16,08 & 5,32 \\
\hline
\end{tabular}

Como as fraçóes de hemicelulose e lignina diminuíram isso pode refletir em uma melhora na conversão enzimática da celulose dessas biomassas, já que essas fraçôes formam uma camada protetora ao redor da celulose, reduzindo assim a eficiência do ataque enzimático.

\section{CONCLUSÃO}

1 - A caracterização da biomassa é de fundamental importância para avaliação do potencial de utilização dessas matérias-primas para a produçáo de etanol de segunda geração, principalmente para definição da fração (celulose e/ou hemicelulose) que será utilizada 
no processo.

2 - Houve grande solubilização das fraçôes hemicelulósica e de lignina, o que é desejável, já que neste estudo o objetivo é a produção de etanol de segunda geração através da fração celulósica.

\section{REFERÊNCIAS}

BARCELOS, C. Aproveitamento das Fraçóes Sacarínea, Amilácea e Lignocelulósica do Sorgo Sacarino [Sorghum bicolor (L.) Moench] para a Produçáo de Bioetanol. 2012. 334f. Tese (Doutorado em Tecnologia de Processos Químicos e Bioquímicos) - Escola de Química, Universidade Federal do Rio de Janeiro, Rio de Janeiro.

BRASIL, Ministério de Minas e Energia. Inventário Energético de Resíduos Rurais. Rio de Janeiro, 2014. Disponível em: < http://www.epe.gov.br/mercado/Documents/S\%C3\%A9rie\%20 Estudos\%20de

\%20 Energia/DEA\%2015\%20-\%2014\%20-\%20\%20 Invent $\%$ C3\% A 1 rio\% 20 Energ\%C3\%A9tico \% 20de\% 20 Res\%C3\%ADduos\%20Rurais.pdf> Acesso em: 09 jul. 2015.

CARMO, J. R. Produçáo de etanol e pectinase por Kluyveromyces marxianus CCT 4086 utilizando resíduos do processamento de café (Coffea arábica L.). 2013. 253f. Tese (Doutorado em Ciência dos Alimentos) - Universidade Federal de Lavras/UFLA, Lavras.

CASTRO, A. M.; PEREIRA JR, N. Produção, propriedades e aplicaçáo de celulases na hidrólise de resíduos agroindustriais. Química Nova, Rio de Janeiro, v.33, p.1-12, 2010.

DUNNING, J.W., DALLAS, D. E. Analytical procedures for control of saccharification process. Analytical Chemistry, Washington, v.21, n.6, p. 727-729, 1949.

FARIAS, S. P.; LEMÖES, J. S.; LEMONS E SILVA, C. F; MESSIAS, R. S.; RUIZ. W. A. Perda de massa de casca de arroz, palha de arroz e Arundo donax L. submetidos à pré-tratamento químico. In: SIMPÓSIO ESTADUAL DE AGROERNERGIA, 5, 2014, Pelotas. Anais.., Embrapa Clima Temperado, 2014.
HICKERT, L. R. Otimização da hidrólise da casca de arroz (Oryza sativa) e a avaliaçáo da capacidade de bioconversáo deste hidrolisado a etanol e xilitol por leveduras. 2010. $117 \mathrm{f}$. Dissertação (Mestrado em Microbiologia Agrícola e do Meio Ambiente) - Universidade Federal do Rio Grande do Sul, Porto Alegre.

LEMONS E SILVA, C. F.; SCHIRMER, M. A.; MAEDA, R. N.; BARCELOS, C. A.; PEREIRA JR, N. Potential of giant reed (Arundo donax L.) for second generation ethanol production. Electronic Journal of Biotechnology, v.18, p.10-15, 2015.

OLIVEIRA, P.A. Caracterizar a Biomassa é fundamental para valorizá-la. 2013. Artigo em Hypertexto. Disponível em: <http://www.infobibos.com/Artigos/2013_1/biomassa/index. htm>. Acesso em: 6 mai. 2015.

ROBERTO, I. C.; MUSSATO, S. I.; RODRIGUES, R. C. L. B. Dilute-acid hydrolysis for optimization of xylose recovery from rice straw in a semi-pilot reactor. Industrial Crops and Products.v.17, p.171-176, 2003.

SANTOS, J. M. C. F. Avaliação da biomassa de plantas bioenergéticas. 2009. 79f. Dissertaçáo (Mestrado em Tecnologias Ambientais) - Instituto Superior de Agronomia, Universidade Técnica de Lisboa, Lisboa.

SLUITER, A; HAMES, B.; RUIZ, R; SCARLATA, C.; SLUITER, J; TEMPLETON, D. Determination of structural carbohydrates and lignin in biomass. Golden, NREL, 2005, $14 \mathrm{p}$.

SOUSA, T. M. Estudo da hidrólise enzimática no tratamento de biomassa lignocelulósica usada como matéria-prima para a produçáo de biocombustível. 2014. 48f. Monografia (Bacharelado em Engenharia Química) - Universidade Federal de Uberlândia, Uberlândia.

SOUZA, G. Q. Caracterizaçáo química do Arundo donax para a obtençáo de etanol 2G. 2014. 43f. Monografia (Bacharelado em Engenharia de Energia) - Universidade de Brasília, Brasília. STAVELA, T.; ARAÚJO, T.; PORTO, E. GranBio inicia produção de etanol de segunda. Disponível em:<http:// www.granbio.com.br/wp-content/uploads/2014/09/partida_ portugues.pdf $>$. Acesso em: 19 mar 2015. 